\title{
Comportamento ingestivo de equinos e a relação com o aproveitamento das forragens e bem-estar dos animais
}

\section{João Ricardo Dittrich ${ }^{1}$, Helen Aline Melo ${ }^{2}$, Amanda Moser Coelho da Fonseca Afonso ${ }^{2}$, Rosangela Locatelli Dittrich ${ }^{3}$}

\author{
${ }_{1}^{1}$ Departamento de Zootecnia da UFPR - Curitiba - PR. \\ 2 Programa de Pós-Graduação em Ciências Veterinárias da UFPR - Curitiba - PR. \\ ${ }^{3}$ Departamento de Medicina Veterinária da UFPR - Curitiba - PR.
}

RESUMO - A sociedade está em novo direcionamento no qual se busca maior respeito nas relações com os animais, tanto na criação e utilização como alimento quanto para outras finalidades, como companhia, esportes, trabalho, entre outros. A domesticação e utilização dos equinos pelo homem proporcionaram a esta espécie inadequado manejo alimentar, principalmente pelo restrito conhecimento do comportamento ingestivo. As pastagens são, reconhecidamente, o ambiente adequado para a alimentação dos cavalos, mas é um sistema complexo que influencia as decisões dos animais em pastejo. O entendimento dos padrões comportamentais dos eqüinos é uma importante ferramenta para o manejo alimentar adequado. O dossel forrageiro é heterogêneo e a estrutura das plantas, como altura, densidade e componentes como folha, colmo e inflorescência, é explorada pelos cavalos por meio da seletividade, a qual permite ao cavalo a ingestão de nutrientes necessários à manutenção e desenvolvimento. Os dois principais fatores limitantes à seletividade são, na maioria das vezes, a oferta de forragem e o tempo de pastejo, resultantes do modelo utilizado na criação e manutenção dos equinos para diversas finalidades. As forragens, além de fontes de nutrientes, são importantes também na prevenção dos problemas clínicos e de desvios comportamentais. O incremento das pesquisas na utilização das pastagens, certamente, mostrará a importante relação entre os cavalos e o meio ambiente e direcionará para práticas de manejo mais adequadas à utilização e melhor qualidade de vida dos cavalos.

Palavras-chave: cavalos, pastos, volumosos

\section{Equine feeding behavior and its relation with forage use and animal welfare}

\begin{abstract}
The society has taken a new direction towards a respectable relationship with the animals and a more conscious breeding, use for food, sports and company. The domestication and the use of horses by people have caused wrong feeding management, which is mainly due to reduced knowledge on feeding behavior. The pastures are the appropriate environment to horses feeding, but it is a complex system which interferes on the horse's decision while it is grazing. The appropriate horse's feeding management depends on the comprehension of their behavior patterns. As the sward is heterogeneous and the plants' structure vary in height, density, types of leaves, stems and reproductive parts, the horses select the sward. This selection allows them to ingest some important nutrients, vital for their maintenance and development. Stocking rate and grazing time, both results of horse management in stables, limit their selectivity. The forages supply nutrients and prevent clinical disorders and behavior stereotypic. Inputs of researches about pasture use are able to show the importance of horses' relationship with environment and the need of appropriate management can provide a better life quality for horses.
\end{abstract}

Key Words: horses, pasture, roughages

\section{Introdução}

A sociedade está em novo direcionamento no qual se busca maior respeito nas relações com os animais, tanto na criação e utilização como alimento quanto para outras finalidades como companhia, esportes, trabalho, etc. Este direcionamento, por obediência às leis ou à própria conscientização, alerta da necessidade de se rever alguns conceitos a respeito de regras e modelos de criação e utilização de animais. Os modelos utilizados até o momento objetivam, na maioria dos casos, índices produtivos superiores ou mesmo particularidades específicas em determinados grupos raciais, sem levar em consideração o desrespeito que estas podem causar aos animais. O desrespeito pode ser observado em inúmeros exemplos, desde o confinamento de gatos ou cães em apartamentos, cavalos em cocheiras para diferentes finalidades, até características raciais que podem prejudicar a saúde e o 
bem-estar de indivíduos pertencentes a determinadas raças. Inúmeras vezes buscamos formas alternativas para estes problemas com ações paliativas, as quais refletem a relação de "domínio" do homem sobre os animais considerados domésticos.

Particularmente na espécie equina, as diferentes formas de utilização, tais como meio de transporte, ferramenta de conquistas, trabalhos e esportes determinaram, desde a domesticação, mudanças na forma de criar e manter os cavalos. As principais mudanças foram a restrição do tamanho das áreas disponíveis ao pastejo, da diversidade de alternativas alimentares e do tempo disponibilizado para o cavalo se alimentar no dia. Estas mudanças desrespeitam uma das principais, se não a principal, particularidade evolutiva desta espécie, o complexo anatômico e fisiológico do aparelho digestório. Esta estratégia de criação e utilização do cavalo desencadeou a simplificação da dieta em duas classes principais de alimentos, os volumosos (pastos e forragens conservadas) e concentrados (alimentos com alto conteúdo energético e/ou protéico), com a preocupação quase que exclusiva de atender as necessidades nutricionais sem levar em consideração aspectos relacionados às formas de disponibilização destes alimentos e o comportamento alimentar dos equinos.

O ambiente adequado de pastagem pode disponibilizar muito mais do que nutrientes, pois permite a liberdade aos animais para expressarem o comportamento natural da espécie e contribuem para diminuir o aparecimento de inúmeros transtornos aos cavalos, como sérios problemas digestivos até vícios de comportamento e, consequentemente, alterações no bem-estar de animais em fazendas de criação e, com maior frequência, em centros de treinamento.

O presente trabalho tem por objetivo discutir o complexo sistema denominado pastagem frente às necessidades dos equinos no que diz respeito à expressão do comportamento, à utilização das forragens como alimento e aos benefícios que este ambiente traz à saúde e, consequentemente, ao bem-estar dos indivíduos.

Comportamento alimentar de equinos em pastagens

\section{Organização do processo de pastejo}

Os equinos são classificados como animais monográsticos, pastejadores de vegetais com grande capacidade de seleção do alimento, alimentando-se predominantemente de folhas, colmos e brotos (Salter \& Hudson, 1979; Ellis \& Hill, 2005). Na análise do processo de pastejo dos herbívoros, adaptado de Stuth (1991), a decisão do cavalo para a colheita da forragem é organizada de forma hierárquica em diferentes etapas, as quais compreendem o amplo ambiente, a comunidade de plantas, o sítio e a estação alimentar, até especificamente a planta. Utilizando esta escala de decisões é possível organizar as informações disponíveis sobre o comportamento dos eqüinos em pastejo e avaliar o conhecimento existente para os diversos segmentos deste processo. Todas as etapas deste processo são importantes e a interferência do homem, por meio do manejo, promove consequências importantes na alimentação, nutrição, saúde e, consequentemente, bem estar.

Estudos a respeito dos padrões de comportamento dos eqüinos livres em pastagens, quando analisados de maneira genérica, apresentam características similares em relação ao tempo destinado à colheita das forragens, à locomoção, ao descanso e às outras atividades sociais. Os valores encontrados correspondem de 10 a 16 horas por dia para o pastejo, com duração de 2 a 3 horas para cada refeição, separadas por intervalos curtos, caracterizados por períodos de descanso, pela locomoção e outras atividades sociais (Tyler, 1972; Duncan, 1980; Dittrich, 2001; Gomes, 2004; Radünz, 2005; Santos et al.,2006; Zanine et al., 2006). Esta similaridade comportamental é uma importante ferramenta para o manejo alimentar de equinos em pastagens, devido à necessidade de tempo para o cavalo decidir nas referidas etapas para a colheita da forragem. O pastejo noturno é de 20 a 50\% do tempo de ingestão diária, influenciado pelas condições ambientais (Doreau et al., 1980; Fleurance et al., 2001; Dittrich, 2001). Imposições de manejo, como o confinamento noturno, alteram os padrões de pastejo. Potros confinados a noite, com concentrado e feno em quantidades não limitantes disponíveis na cocheira, pastam por mais tempo a tarde, quando comparado a outros que permanecem todo tempo no pasto (Sá Neto et al., 2008). Éguas soltas durante 24 horas pastejam proporcionalmente mais tempo do que aquelas presas durante 12 horas (Pond, 1993). A limitação do tempo destinado ao pastejo pela manutenção de cavalos em cocheira, mesmo que somente no período noturno, diminui o tempo diário de alimentação, aumenta o tempo ocioso (Pond, 1993) e desencadeia aumento na frequência de estereotipias (Johnson et al., 1998), o que prejudica a saúde geral dos animais.

O tempo destinado à colheita da forragem está relacionado às características dos animais, como estado fisiológico, e das características ambientais. Éguas em lactação utilizam em média 59\% do dia para o pastejo e 40\% para descanso e outras atividades (Rifá, 1990). A estação do ano também interfere no comportamento em pastejo, alterando a preferência devido à sucessão estacional das espécies forrageiras ou modificando os padrões do período 
e do tempo das refeições (Mayes \& Duncan, 1986; Putman, et al., 1987). As características raciais e o sistema de lotação utilizado (contínuo ou rotacionado) não interfrem no tempo de pastejo (Almeida et al., 1999; Gudmundson \& Dyrmundsson, 1994; Lobo et al., 2009).

O entendimento de como os eqüinos exploram o dossel forrageiro pode determinar o impacto do pastejo nas espécies presentes, na sucessão da comunidade vegetal e incrementar a produção das pastagens, conseqüentemente, dos animais. Os cavalos diferenciam-se de outros herbívoros porque são altamente seletivos, consumindo uma extensa ordem de plantas e até raízes. Utilizam como base da sua seleção a preferência e praticam a seletividade nas estruturas das diferentes espécies de plantas (Collery, 1974).

Preferência, seletividade e velocidade na colheita da forragem

Define-se preferência como a discriminação entre os diferentes componentes do pasto acessíveis aos animais, havendo oportunidade de livre escolha. A identificação da preferência de herbívoros em pastejo tem sido realizada oferecendo-se aos animais faixas homogêneas de diferentes espécies (puras ou em misturas) e componentes forrageiros, avaliando-se a proporção do total ingerido de cada espécie, componente da forragem ou a proporção do tempo de pastejo gasto em cada faixa. As variações na preferência de herbívoros são influenciadas por características da planta como a espécie vegetal, estrutura (altura, presença de material morto, resistência e/ou altura do pseudocolmo) e características do animal como experiência prévia de pastejo, jejum e variações individuais (Dumont, 1997).

Devido à influência das características vegetais na preferência dos equinos os trabalhos realizados neste tema têm apresentado resultados bastante variáveis. Os primeiros trabalhos mostraram maior preferência dos equinos às gramíneas em detrimento de leguminosas e outros tipos de vegetais (Archer, 1973). Diversos outros autores realizaram novos ensaios e identificaram que as gramíneas temperadas, Lolium multiflorum (azevém), Dactylis glomerata, Poa pratensis, e Bromus sp., são preferidas por cavalos quando comparadas a outras, como Festuca, Avena (aveia), Phalaris, Triticum, Triticale e Secale (Archer, 1973; Hunt e Hay, 1989; McCann e Hoveland, 1991; Hughes e Gallagher, 1993; 1998; Gomes, 2004). Da mesma forma que entre as gramíneas, os eqüinos também têm mostrado preferência entre espécies de leguminosas. Os gêneros de leguminosas mais utilizados na alimentação de eqüinos são Trifolium, Medicago, Vicia e Lotus (Benyovszky, 1998). Entre as de clima temperado a mais preferida é Trifolium repens (trevo branco) (McCann \& Hoveland, 1991; Dittrich et al., 2007) e o Lotus corniculatus (cornichão) é de baixa aceitabilidade (Dittrich et al., 2005).

As informações relativas à preferência entre espécies forrageiras apropriadas à alimentação de eqüinos em clima subtropical e tropical são escassas. Os gêneros mais utilizados são Pennisetum spp., Digitaria spp., Chloris spp., Paspalum spp., Cynodon spp., Panicum spp. e Brachiaria spp. para gramíneas, e Desmodium spp., Glycine spp., Lotononis spp. e Macroptilium spp. para leguminosas (Elphinstone, 1981; Carvalho \& Haddad, 1987; Nunes et al., 1990; Webb et al. 1990). Especificamente no gênero Cynodon spp., os eqüinos preferem o Tifton 85, Coastcross 1 e Jiggs em relação ao Tifton 68 e ao Tifton 44, enquanto a Estrela Roxa e a Porto Rico são preteridas (Dittrich et al., 2001; Radünz, 2005).

A composição botânica da pastagem é uma importante variável na decisão do animal para a escolha do local de pastejo. Os eqüinos preferem sítios de pastejo onde há mistura de espécies forrageiras, gramíneas e leguminosas, despendendo maior tempo de pastejo nestes sítios, do que sítios de pastejo onde as mesmas espécies encontram-se puras (Dittrich et al., 2005). A seleção da dieta é identificada pela aceitação ou rejeição de certos componentes da pastagem (plantas ou partes das plantas), sendo de grande importância para a nutrição e produtividade dos eqüinos. As características estruturais das plantas, como altura, densidade e componentes como folha, colmo e inflorescência, interferem nesta seleção (Hughes \& Gallagher, 1993; Dittrich, 2005) e determinam a probabilidade dos seus componentes serem removidos pelo animal na realização de um bocado. A altura da pastagem é uma das variáveis mais importantes na decisão de equinos em pastejo e a escolha dos animais por sítios de pastejo com maior ou menor altura tem interpretação confusa. Os cavalos selvagens, mantém sítios de menor altura e despendem maior tempo em pastejo nos mesmos (Ménard et al., 2002), mas esta estratégia pode estar relacionada a evitar o pastejo em áreas de gramíneas altas contaminadas com fezes (Putman et al., 1987). Em pastagens cultivadas e livres de contaminação prévia por fezes, a escolha dos equinos é por dosséis mais altos e por plantas mais altas, demonstrada pelo maior tempo de pastejo nos dosséis de maior altura e por seleção de plantas mais altas, individualmente, os quais proporcionam maior dimensão de forragem colhida a cada bocado, tanto para gramíneas temperadas (Naujeck \& Hill, 2003; Naujeck et al., 2005) quanto para gramíneas tropicais (Dittrich et al., 2005). As duas principais estruturas das plantas (folhas e caules) refletem também a qualidade do alimento colhido pelo cavalo. A seletividade em pastejo pode ser demonstrada 
pela preferência por dosséis e plantas com maior massa de folhas em relação à de caules (Dittrich et al., 2005), o que proporciona maior qualidade nutricional a cada bocado, estratégia de seletividade, presente desde os primeiros ancestrais da espécie eqüina (Ellis \& Hill, 2005).

As práticas de manejo das pastagens como cercas, espécies utilizadas, massa de forragem disponível, pressão de pastejo, dos cavalos como confinamento parcial, exercícios físicos e do manejo de suplementação com alimentos concentrados, impõem aos animais a necessidade de adaptação à realidade cotidiana imposta aos mesmos pelo homem. Em consequência, a velocidade de colheita da forragem para a mastigação e deglutição é dependente de inúmeros fatores, mas o tempo disponibilizado à colheita da forragem é a variável determinante da massa e da qualidade da forragem ingerida. A velocidade de colheita da forragem pode ser aferida pelo número de movimentos de colheita da forragem (bocados) nos sítios de pastejo (Hodgson, 1982). Em eqüinos de distintas raças, em sistema de criação comercial com pastagens cultivadas tropicais e temperadas, a variação da velocidade de colheita é de 18 a 26 bocados por minuto. Estes valores estão relacionados com a altura do pasto, sendo que menores alturas necessitam de mais bocados para uma mesma massa de forragem colhida e com a espécie vegetal, pois leguminosas e gramíneas temperadas são mais facilmente colhidas proporcionando maior velocidade de ingestão (Duren et al., 1989; Marinier e Alexander, 1992; Gomes, 2004; Dittrich et al., 2005). A velocidade de colheita em estruturas vegetais semelhantes, como espécie e altura, tem se apresentado sem variações significativas, independente do sistema de lotação utilizado. Em lotação rotacionada, esta característica comportamental pode diminuir a seletividade dos cavalos no dossel forrageiro e, consequentemente, o valor nutritivo da dieta (Lobo et al., 2009).

\section{Aporte nutricional das pastagens}

Quando se avalia o aporte nutricional das pastagens, uma das publicações mais utilizadas é o National Research Council (NRC), o qual publica estimativas dos requerimentos médios diários de nutrientes para equinos, em diferentes condições físicas e fisiológicas, como em crescimento, manutenção, reprodução, lactação e trabalho. Além dos requerimentos diários há também a ingestão voluntária diária, a qual por vários métodos é estimada na amplitude de 1,5 a 3,1\% da massa corporal (NRC, 2007). A certeza do aporte nutricional das pastagens em quantidade e qualidade dos nutrientes requeridos é uma questão complexa e deve ser mais estudada. A pastagem é um ambiente heterogêneo resultante das características físicas e químicas do solo, das espécies que a compõe, do estádio de desenvolvimento das plantas e das estações climáticas, devendo ser disponibilizada aos cavalos para permitir a ingestão voluntária diária mínima. Estas variáveis estão associadas à pressão de pastejo que é fruto do manejo aplicado. As espécies que compõem as pastagens são compostas por partes denominadas de pecíolos, folhas, bainhas, lâminas, colmos e inflorescências. Cada parte difere na estrutura, na proporção relativa que a compõe e na composição química durante os estádios de desenvolvimento, resultando em dosséis heterogêneos (Singer et al., 1999). Os cavalos exploram esta heterogeneidade por meio da seletividade nas plantas individualmente, consumindo as mais novas, as de meristema apical mais próximo ao solo e, consequentemente, maior proporção de folhas em relação a colmos (Tezza et al., 2009) e maior digestibilidade (Coleman, 1992). O aporte nutricional é dependente da participação de cada estrutura no dossel forrageiro e, também, do tempo disponibilizado para os animais o explorarem.

O aporte protéico das pastagens varia entre as espécies utilizadas, com as condições ambientais (Johnson et al., 2001), com o estádio de desenvolvimento e mesmo entre as partes das plantas selecionadas pelos cavalos (Oowen et al., 1978). As proteínas são encontradas em maior concentração nas folhas do que nos colmos (Collins, 1988). A proteína contida na maioria das pastagens é suficiente para suprir os requerimentos nutricionais de equinos em diferentes estados fisiológicos, principalmente para animais adultos, não em reprodução (Elphinston, 1981; Hughes \& Gallagher, 1993). O aporte protéico das leguminosas é, na média, superior ao das gramíneas hibernais (de clima temperado) e ao das estivais (de clima tropical) (NRC, 2007). As leguminosas quando presentes nas pastagens são consumidas e participam da dieta dos cavalos, promovendo incremento do conteúdo de proteína diário (Dittrich, 2005). Quando fornecida como única fonte de alimento da dieta pode veicular conteúdos diários excessivos aos equinos (Almeida, 1999).

As espécies vegetais caracterizam-se por apresentar, entre as partes que as compõem, diferentes conteúdos de fibra, representados por carboidratos estruturais, variadas quantidades de lignina e, também, carboidratos não estruturais como açúcares simples, amido e frutanas, originados do conteúdo celular. Os carboidratos estruturais e não estruturais constituem-se no principal aporte energético da forragem. Amido e açúcares simples podem ser digeridos por enzimas endógenas no intestino delgado e os carboidratos estruturais e frutanas não são digeridos por estas enzimas, mas são importantes fontes energéticas 
por meio da digestão microbiana no ceco resultando na produção de acetato, propionato e butirato (NRC, 2007). Devido à baixa concentração de mono, di e oligossacarídeos nas plantas, os polissacarídeos, principalmente a celulose, hemicelulose e amido, nesta ordem de importância, estão presentes na dieta dos equinos em pastagens e, consequentemente, são as principais fontes de energia para os cavalos que se alimentam exclusivamente de pastagem (Moore-Colyer et al., 2000).

A restrição do tempo de pastejo e/ou a baixa oferta de forragem limitam a ingestão de forragem pelos animais e, consequentemente, de uma dieta com conteúdos adequados de vários nutrientes, principalmente os carboidratos estruturais, também denominados fibras. As fibras formam a base da dieta de equinos e há muitas evidências da importância do conteúdo de fibra na dieta para prevenção de acidoses (Medina et al., 2002), cólicas (Tinker et al., 1997) úlceras gástricas (Murray et al., 1989) e os desvios comportamentais (Gillham, et al., 1994). Os dois principais fatores limitantes na alimentação dos equinos são a oferta de forragem e tempo de pastejo, na maioria das vezes, resultados do modelo utilizado na criação e manutenção dos cavalos para as mais diversas finalidades. A oferta de forragem insuficiente por ausência de áreas adequadas nas propriedades para o número de animais criados ou pela falta de planejamento e cuidados necessários para o estabelecimento, escolha de espécies, cultivo e adequados sistemas de utilização das pastagens. O tempo de pastejo restrito pela necessidade do confinamento em cocheiras necessário à rotina dos treinamentos dos cavalos para esporte, principalmente, nos centros hípicos. A falta de planejamento para o controle destas duas variáveis, aliada à necessidade de alto aporte energético para os cavalos com atividade física intensa, teve com consequência maior preocupação na nutrição de equinos baseada em dietas com conteúdos maiores de energia, ricas em amido. Muitos tipos de grãos de cereais e seus subprodutos vêm sendo utilizados na alimentação de cavalos (NRC, 2007). A utilização de dietas ricas em amido na alimentação de cavalos pode causar problemas digestivos e metabólicos aos equinos, tanto pela limitada ação enzimática no intestino delgado e consequente fermentação rápida no intestino grosso com risco de endotoxemia, cólica e laminite, quanto pelo distúrbio metabólico denominado resistência à insulina, identificada em cavalos obesos e de pouca atividade física (Hoffman et al., 2003; Hoffman, 2009).

\section{Alimentação volumosa para cavalos em confinamento}

A necessidade da utilização de volumosos na dieta dos cavalos é indiscutível, mesmo para animais em treinamento quando há alto requerimento energético e impossibilidade de acesso a áreas de pastagem. Os fenos são os principais alimentos volumosos conservados utilizados nestas situações, mas pesquisas vêm sendo desenvolvidas na busca de alternativas como silagens, pré-secados ou mesmo subprodutos da indústria como exemplo, a polpa cítrica e casca de soja (Quadros et al., 2004; Brandi \& Furtado, 2009). A não utilização destes alimentos volumosos conservados ainda é devida à insegurança com a qualidade do produto, muitas vezes elaborado e conservado de forma inadequada (Domingues, 2009). O consumo de silagem como única forma de alimento foi avaliada por Melo (2007) e verificou-se que o tempo destinado pelos animais ao consumo de três tipos de silagem “ad libitum” variou de 8,8 a 10 horas por dia, com maior tempo no período diurno em relação ao noturno. Os animais consumiram somente silagem por 27 dias sem alterações clínicas, hematológicas e dos perfis bioquímicos hepático e renal, demonstrando que este alimento conservado pode ser utilizado na alimentação de cavalos.

A necessidade do confinamento em cocheiras, devido à rotina dos treinamentos dos cavalos para esporte, principalmente nos centros hípicos vem sendo motivo de estudo com o objetivo de propiciar aos animais melhores condições de alimentação, nutrição, saúde física e mental e, consequentemente, bem-estar.

O manejo alimentar de cavalos estabulados, que geralmente recebem grandes quantidades de alimento concentrado, tem importante influência sobre o seu comportamento geral e mais especificamente sobre o alimentar. Se a quantidade de alimentos volumosos oferecida aos animais é insuficiente, os indicadores de saciedade podem não ser ativados e os cavalos permanecem com alta motivação à procura de alimentos (McGreevy et al., 1995). Johnson et al. (1998) observaram que altas proporções de alimentos concentrados na dieta de eqüinos confinados, aumentaram a incidência de distúrbios orais de comportamento (estereotipias), como morder grade/muro, lamber cocho/grade e comer a cama. A carência de alimentos volumosos na dieta, além dos problemas de desvios comportamentais, está também relacionada com problemas de saúde incluindo ulcerações gástricas, cólicas e laminites (Davidson \& Harris, 2002; Mills, 2005; NRC, 2007).

A manutenção dos cavalos em cocheiras por longos períodos priva-os de adequada movimentação na busca de alimentos, das relações sociais com outros animais e, consequentemente, a maior parte do tempo os animais permanecem em pé e com atitudes comportamentais inadequadas (Goloubeff, 1993; Rezende et al., 2006). O 
confinamento impõe acentuadas mudanças comportamentais, denominadas estereotipias, quando comparadas aos cavalos mantidos em pastagens. Evidências recentes sugerem que esses comportamentos são respostas ao ambiente de cocheiras, associado ao manejo e predisposição individual (Mills, 2005). A hipótese de que as estereotipias são indicadores das deficiências ambientais e do baixo grau de bem-estar têm sido amplamente discutida. Entre as estereotipias há comportamentos orais atípicos como a coprofagia, a geofagia e comer pedaços de cascas de árvore, cercas, cama da baia, etc. A coprofagia pode ser normal em potros, principalmente na fase de colonização da flora bacteriana que habita naturalmente o trato gastrointestinal (Boyd, 2005; Johnson et al., 1998; Waters et al., 2002). Fortes evidências apontam a relação entre os fatores de manejo, baixa quantidade de alimentos volumosos na dieta e isolamento social com o comportamento estereotípico em cavalos estabulados (McGreevy et al, 1995; Cooper et al., 2000). É de consenso entre os pesquisadores que o fornecimento de alimentos volumosos aos animais estabulados é uma importante ferramenta para a manutenção da saúde física e mental dos cavalos, pois este tipo de alimento é de ingestão lenta (NRC, 2007) e permite aos animais, mesmo estabulados, expressar o comportamento alimentar mais similar a dos animais em liberdade. Forma alternativa de fornecimento lento de volumosos para cavalos estabulados foi proposta por Winskill (1996). Além da ingestão lenta, a variabilidade alimentar de volumosos para cavalos estabulados no que diz respeito à forma apresentada ou a espécie pode ser mais estudada. Afonso (2010) avaliou o comportamento alimentar de equinos em treinamento, alimentados com volumosos de uma mesma espécie (Pennisetum purpureum) oferecidos de duas formas, picado e inteiro. Observou-se que a oferta não limitante da mesma forragem de diferentes formas não induziu maior motivação alimentar nos animais estabulados. A mudança de ambiente para o piquete, com os mesmos alimentos e com acesso a uma área de pasto de Brachiaria decumbens, permitiu a interação social entre os animais. O tempo em consumo na área de pastagem foi maior do que nos volumosos oferecidos sob as duas formas. A colheita da forragem na forma de pasto, sem manipulação humana, é a preferida pelos cavalos, pois permite maior interação entre os indivíduos e o meio ambiente. O aprofundamento no estudo do comportamento, principalmente o alimentar, de eqüinos estabulados é de extrema importância e pode nortear as decisões relativas ao adequado manejo dos animais.

\section{Considerações finais}

A importância da utilização dos alimentos volumosos para os equinos, tanto na criação, quanto em atividade esportiva ou trabalho, muitas vezes é substituída pela utilização de concentrados comerciais os quais influenciam as decisões do criador ou proprietário no estabelecimento do manejo alimentar. De maneira simplista, deixa-se em segundo plano a importância que os alimentos volumosos têm na alimentação dos cavalos, referindo-se a este alimento como fonte de fibra, exclusivamente. O que levou a este conceito foi, provavelmente, o desconhecimento ou a desconsideração das relações do meio ambiente com o comportamento, a nutrição e bem-estar dos equinos. O avanço científico nos estudos da utilização de alimentos concentrados na nutrição dos cavalos é inquestionável e de extrema importância, mas há um novo direcionamento no sentido de valorizar também os volumosos na dieta, tanto nas características nutricionais quanto no respeito aos hábitos alimentares dos equinos.

A complexidade do ambiente denominado pastagem, pode ser um dos motivos pelo qual há reduzido número de trabalhos científicos com cavalos envolvendo este tema, ou pela dificuldade dos pesquisadores e profissionais em relacionar as diferentes faces do conhecimento. O incremento das pesquisas na utilização das pastagens, certamente mostrará a importante relação que os cavalos têm com o meio ambiente e direcionará para práticas de manejo mais adequadas à utilização e melhor qualidade de vida dos cavalos.

\section{Referências}

AFONSO, A.M.C.F. Comportamento alimentar de equinos em treinamento submetidos a três manejo. $201075 \mathrm{f}$. Dissertação (Mestrado em Ciências Veterinárias) - Universidade Federal do Paraná, 2010.

ALMEIDA, M.I.V.; FERREIRA, W.M.; ALMEIDA, F.Q. et al. Valor nutritivo do capim-elefante (Pennisetum purpureum, Schum), do fento de alfafa (Medicago sativa, L.) e do feno de capim coast-cross (Cynodon dactylon, (L.) Pers.) para equinos. Revista Brasileira de Zootecnia, v.28, n.4, p.743-752, 1999.

ARCHER, M. The species prefetences of grazing horses. Journal British Grassland Society, v.28, p.123-128, 1973.

BENYOVSZKY, B.M. Grassland palatability study with horses. In: ECOLOGICAL ASPECTS OF GRASSLAND MANAGEMENT, MEETING, 7., 1998. Proceedings... s.l.: 1998, p.635-638.

BOYD, L.; DEIPER, R. Behaviour ecology of feral horse. IN: The domestic horse: the evolution, development and management of it's behaviour. Cambridge: Cambridge University Press, 2005. p.55-82.

BRANDI, R.A.; FURTADO, C.E. Importância nutricional e metabólica da fibra na dieta de equinos. In: REUNIÃO ANUAL DA SOCIEDADE BRASILEIRA DE ZOOTECNIA, 46., 2009, Maringá. Anais... Maringá: Sociedade Brasileira de Zootecnia, 2009. p.246-258. 
CARVALHO, R.T.L.; HADDAD, C.M. Pastagens e alimentação de eqüinos. Piracicaba: Fundação de Estudos Agrários Luiz de Queiroz, 1987. 85p.

COLeman, S.W. Plant-animal interface. Journal of Productive Agriculture, v.5, p.7-13, 1992.

COLLERY, L. Observations of equine animals under farm and feral conditions. Equine Veterinary Journal, v.6, p.170-173, 1974

COLLINS, M. Composition and fiber digestion in morphological components of an alfafa/timothy hay. Animal Feed Science Technology, v.19, p.135-143, 1988.

COOPER,J.J; McDONALD, L.; MILLS, D.S. The effect of increasing visual horizons on stereotypic weaving: implications for the social housing of stabled horses. Applied Animal Behaviour Science, v.69, p.67-83, 2000.

DAVDSON, N.; HARRIS, P. Nutrition and welfare. In: _- The welfare of horse. Dordrecht: Kluwer Academic Publishers, 2002. v.1, p.45-76.

DITTRICH, J.R. Relações entre a estrutura das pastagens e a seletividade de eqüinos em pastejo. 2001. 77f. Tese (Doutorado em Agronomia) - Universidade Federal do Paraná, 2001.

DITTRICH, J.R.; CARVALHO, P.C.F.; MORAES, A. et al. Preferência de eqüinos em pastejo: efeito da altura de dosséis de gramíneas do gênero Cynodon. Archives of Veterinary Science, v.10, n.2, p.61-67, 2005.

DITTRICH, J.R.; CARVALHO, P.C.F.; MORAES, A. et al Comportamento ingestivo de eqüinos em pastejo sobre diferentes dosséis. Ciência Animal Brasileira, v.8, n.1, p.8794, 2007.

DOMINGUES, J.L. Uso de volumosos conservados na alimentação de equinos. In: REUNIÃO ANUAL DA SOCIEDADE BRASILEIRA DE ZOOTECNIA, 46., 2009, Maringá. Anais... Maringá: Sociedade Brasileira de Zootecnia, 2009. p.259-269.

DOREAU, M.; MARTIN-ROSSET, W.; PETIT, D. Nocturnal feeding activities of horses at pasture. Annales de Zootechine, v.29 p.299-304, 1980

DUMONT, B. Diet preferences of herbivores at pasture. Annales de Zootechnie, v.46, p.105-116, 1997.

DUNCAN, P. Time-budgets of Camargue horses. II. Time-budgets of adult horses and weaned sub-adults. Behaviour, v.72, p.2649, 1980

DUREN, S.E.; DOUGHERTY, C.T.; JACKSON, S.G. et al. Modification of ingestive behavior due to exercise in yearling horses grazing orchardgrass. Applied Animal Behaviour Science, v.22, p.335-345, 1989.

ELLIS, A.D.; HILL, J. Nutritional physiology of the horse. Nottingham: Nottingham University Press, 2005. 361p.

ELPHINSTONE, G.D. Pastures and fodder crops for horses in southern coastal queensland. Queensland Agricultural Journal, v.107, p.122-126, 1981.

FLELURANCE, G.; DUNCAN, P.; MALLEVAND, B. Daily intake and the selection of feeding sites by horses in heterogeneous wet grasslands. Animal Research, v.50, p.149-156, 2001.

GILHAM, S.B.; DODMAN, N.H., SHUSTER, L. et al. The effect of diet on cribbing hehaviour and plasma beta-endorphin in horses. Applied Animal Behaviour Science, v.41, p.147-153, 1994.

GOLOUBEFF, B. Distúrbio do comportamento alimentar. In: GOLOUBEFF, B. (Ed.) Abdome agudo eqüino. São Paulo: Varela, 1993. p.17-21.

GOMES, C.S. Azevém e aveia branca como fator de influência no comportamento ingestivo de eqüinos. 2008 53f. Dissertação (Mestrado em Agronomia) - Universidade Federal do Paraná, Curitiba.

GUDMUNDSON, O.; DYRMUNDSSON, O.R. Horse grazing under cold and wet conditions: a review. Livestock production Science, v.40, p.57-63, 1994.

HODGSON, J. Ingestive behaviour. In: LEAVER, J.D. (Ed.) Herbage intake handbook. s.l.: The British Grassland Society, 1982. p. 113-138.
HOFFMAN, R.M. Carbohydrate metabolism and metabolic disorders in horse. In: REUNIÃO ANUAL DA SOCIEDADE BRASILEIRA DE ZOOTECNIA, 46., 2009, Maringá. Anais... Maringá: Sociedade Brasileira de Zootecnia, 2009. p.270-276.

HUGHES, T.P.; GALLAGHER, J.R. Influence of sward height on the mechanics of grazing and intake by racehorses. In: INTERNATIONAL GRASSLAND CONGRESS, 17., 1993, Palmerston North. Proceedings... Palmerston North, 1993. p.1325-1326.

HOFFMAN, R.M.; BOSTON, R.C.; STEFANOVSKI, D. et al. Obesity and diet afeect glucose dynamics and insulin sensitivity in thoroughbred geldings. Journal of Animal Science, v.81, p.2333-2342, 2003.

HUNT, W.F.; HAY, R.J.M. Pasture species preferences by horses in New Zealand. In: INTERNATIONAL GRASSLAND CONGRESS, 16., 1989, Nice. Proceedings... Nice, 1989. p.797-798.

JOHNSON, K.G.J. et al. Behavior changes in stable horses given nontherapeutic levels of virginiamycin. Equine Veterinary Journal, v.30. p.139-143, 1998.

JOHNSON, C.R.; REILING, B.A.; MISLEVY, P.; HALL, M.B. Effects of nitrogen fertilization and harvest date on yield, digestibility, fiber, and protein fractions of tropical grasses. Journal Animal Science, v.79 p.2439-2448, 2001.

LOBO, A.H.; CASSANELLI, F.; SWAROSKI, D. et al. Comportamento alimentar de éguas da raça Mangalarga Marchador em sistemas de lotação contínua e rotacionada. In: SIMPÓSIO DE EQUIDEOCULTURA, 2., 2009, Viçosa, MG. Anais... Viçosa, MG: Universidade Federal de Viçosa, 2009. p.191.

MARINIER, S.L.; ALEXANDER, A. J. Use of field observations to measure individual grazing ability in horses. Applied Animal Behaviour Science, v.33, p.1-10, 1992.

MAYES, E.; DUNCAN, P. Temporal patterns of feeding behaviour in free-ranging horses. Behaviour, v.96, p.105-129, 1986.

McCANN, J.S.; HOVELAND, C.S. Equine grazing preferences among winter annual grasses and clovers adapted to the southeastern United States. Equine Veterinary Science, v.11, p.275-277, 1991.

MCGREEVY, P. et al. Management factors associated with stereotypic and redirected behavior in Thoroughbred horse. Equine Veterinary Journal, v.27, n.2, p.86-91, 1995.

MEDINA, B.; GIRARD, I.D.; JACOTOT, E.; JULLIAND, V. Effect of a preparation of Saccharomyces cerevisiae on microbial profiles and fermentation patterns in the large intestine of horses fed a high fiber or a high starch diet. Journal Animal Science, v.80, p.2600-2609, 2002.

MELO, H.A. Consumo, preferência alimentar, monitoramento clínico, hematológico e bioquímico de equinos alimentados com silagem. 2008. 53f. Dissertação (Mestrado em Ciências Veterinárias) - Universidade Federal do Paraná, Curitiba.

MÉNARD, C.P.; DUNCAN, P.; FLEURANCE, G. et al. Comparative foranging and nutrition of horses and cattle in European wetlands. Journal of Applied Ecology, v.39, p.120-133, 2002.

MILLS, D.S. Repetitive movement problems in the horse. In: The domestic horse: the evolution, development and management of it's behaviour. Cambridge: Cambridge University Press, 2005. p.212-227.

MOORE-COLYER, M.J.S.; HYSLOP, J.J.; LONGLAND, A.C. et al. Intra-cecal fermentation parameters in ponies fed botanically diverse fibre-based diets. Animal Feed Science Thecnology. v.84, p.183-197, 2000.

MURRAY, M.J.; GRODINSKY, C.; ANDERSON, C.W. et al. Gastric ulcers in horses: a comparison of endoscopic findings in horses with and without clinical signs. Equine of Veterinary Journal. Suppl. 7, p.68-72, 1989.

NATIONAL RESEARCH COUNCIL - NRC. Nutrients requirements of domestic horses. 6.ed. Washington, D.C.: National Academy of Scince, 2007. 341p. 
NAUJECK, A.; HILL, J. Influence of sward height on bite dimensions of horses. Animal Science, v.77, p.95-100, 2003.

NAUJECK, A.; HILL, J.; GIBB, M.J. Influence of sward height on diet selection by horses. Animal Science, v.77, p.95-100, 2005.

NUNES, S.G.; SILVA, J.M.; QUEIROZ, H.P. Avaliação de gramíneas forrageiras para eqüinos. Campo Grande: Embrapa Gado de Corte, 1990. p.1-5. (Documentos, 45).

OOWEN J.M.; McCULLAGH K.G.; CROOK, D.H. Seasonal variations in the nutrition of horses at grass. Equine Vetrinary Journal, v.10, p.260-266, 1978.

POND, K.R., D.K.; DUGAN, D.T.; BARNEET, J.C. et al. Grazing behavior of mares and steers on orchardgrass and mares on common bermuda grass. In: EQUINE NUTRITION AND PHYSIOLOGY SYMPOSIUM, 14., 1993, s.l. Proceedings... s.l.: 1993. p.236.

PUTMAN, R.J.; PRATT, R.M.; EKINS, J.R.et al. Food and feeding behaviour of cattle and ponies in the New Forest Hampshire. Journal of Applied Ecology, v.24, p.369-380, 1987.

QUADROS, J.B.Q.; FURTADO, C.E.; BARBOSA, E.D. et al. Digestibilidade aparente e desenvolvimento de equinos em crescimento submetidos a dietas compostas por diferentes níveis de substituição do feno de Tifton 85 pela casca de soja. Revista Brasileira de Zootecnia, v.33, n.3, p.564-574, 2004.

RADÜNZ, E. A estrutura de gramíneas do gênero Cynodon e o comportamento ingestivo de eqüinos. 2008. 48f. Dissertação (Mestrado em Ciências Veterinárias) - Universidade Federal do Paraná, Curitiba.

REZENDE, M.J.M. et al. Comportamento de cavalos estabulados do exército brasileiro em Brasília. Ciência Animal Brasileira, v.7, n.1, p.17-25, 2006.

RIFÁ, H. Social facilitation in the horse (Equus caballus). Applied Animal Behaviour Science, v.25, p.167-176, 1990.

SÁ NETO, A.; SWAROSKI, D.; LOBO, A. H. et al. Comportamento alimentar de potros da raça Mangalarga Marchador submetidos a dietas em cocheira e em pastagem de Hemártria. In: REUNIÃO ANUAL DA SOCIEDADE BRASILEIRA DE ZOOTECNIA, 2008, 45., Lavras. Anais... Lavras: Sociedade Brasileira de Zootecnia/Gmosis, [2008]. CD-ROM. Forragicultura. C-637.
SALTER, R.E.; HUDSON, R.J. Feeding ecology of feral horses in western Aberta. Journal of Range Management, v.32, p.221-225, 1979.

SANTOS, E.M.; ZANiNE, A.M.; PARENTE, H.N. et al. Comportamento ingestivo de eqüinos em pastagens de grama batatais (Paspalum notatum) e braquiarinha (Brachiaria decumbens) na região centro-oeste do Brasil. Ciência Rural, v.36, n.5, p.1565-1569, 2006.

SINGER, J.W.; BOBSIN, N.; BAMKA, W.J. et al. Horse pasture management. Journal of Equine Veterinary Science, v.19, n.9, 1999.

STUTH, J.W. Foraging behavior. In: HEITSCHMIDT, R.K.; STUTH, J.W. (Eds.) Grazing management: an ecological perspective. Oregon: Timber Press, 1991. p.85-108.

TEZZA, L.B.L.; LOBO, A.H.; KLOSS, A.B. et al. Características da seletividade de equinos em pastagem de aveia preta (Avena satrigosa). In: SIMPÓSIO DE EQUIDEOCULTURA, 2., 2009, Viçosa, MG. Anais... Viçosa, MG: Universidade Federal de Viçosa, 2009. p.185.

TINKER, M.K.; WHITE, N.A., LESSARD, P. et al. Prospective study of equine colic risk factors. Equine of Veterinary Journal, v.29, p.454-458, 1997.

TYLER, S.J. The behaviour and social organization of the New Forest ponies. Animal Behaviour Monogastric, v.5, p.8596, 1972.

WATERS, F.J.; NICOL, C.J.; FRENCH, N.P. Factors influencing the development of stereotypic and redirected behaviours in young horses: findings of a four year prospective epidemiological study. Equine Veterinary Journal, v.34, p.572-579, 2002.

WEBB, G.W.; HUSSEY, M.A.; CONRAD, B.E. et al. Growth of yearling horses grazing klein grass or Bermuda grass pastures. Equine Nutrition and Physiology Society, v.10, p.195-198, 1990.

WINSKILL, L.C.; WARAN, N.K.; YOUNG, R.J. The effect of a foraging device (a modified "Edinburgh Foodball") on the begaviour of stabled horse. Applied Animal Behaviour Science, v.48, p.25-35, 1996.

ZANINE, A.M.; SANTOS, E.M.; PARENTE, H.N. et al. Diferenças entre sexos para as atividades de pastejo de eqüinos no nordeste do Brasil. Archivos de Zootecnia, v.55, n.210, p.139-147, 2006. 